\title{
Photovoltaic (PV) and Thermo-electric energy harvesters for charging applications
}

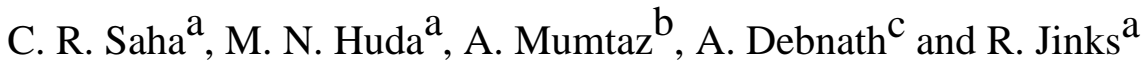 \\ ${ }^{a}$ School of Computing, Electronics and Mathematics, Coventry University, UK.

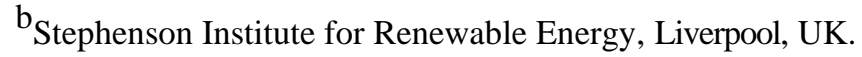 \\ ${ }^{\mathrm{C}}$ Asian University for Women, Chittagong, Bangladesh.
}

Abstract - Significant technical progress is currently ongoing in the field of energy harvesting technologies. This paper presents a study of both photovoltaic (PV) and thermo-electric energy harvesting techniques in the context of mobile phone applications. The paper includes performance analysis of a macro scale PV module and a thermo-electric generator (investigated under different conditions), together with a single diode electrical equivalent circuit model of the solar PV developed using MATLAB/Simulink. Additionally experimental results of the PV module are verified via simulation. To complete the study a PV module is integrated with a DC/DC adjustable converter and solar charge controller (3A CMTP02) to charge a smart mobile phone in order to assimilate charging capacity and feasibility of macro scale energy harvesting devices.

Keywords - Energy harvesters, Solar PV, Thermoelectric, mobile charging.

\section{Introduction and Review}

There has been a growing in interest in energy harvesting technology over the last few years, due in the main to an increased demand requirement for the use of sustainable power supplies in emerging technologies. For example in the realm of Internet of Things (IoT [1], embedded systems [2], environmental monitoring [3], wireless sensor networks (WSNs), smart cities [4], wearable and portable electronics [5] to name a few. Electrical energy can be obtained via energy harvesting technology from a variety of ambient sources, such as solar irradiance, thermal (e.g. waste heat), electromagnetic waves (including radio frequency), wind, water waves, vibration and the human effects such as motion [1].

Electronic devices powered via an energy harvester, can be classified mainly into four groups based on their power requirements, namely high power $(\geq 10 \mathrm{~W})$, medium power $(1 \mathrm{~W}-10 \mathrm{~W})$, low power $(1 \mathrm{~mW}-1 \mathrm{~W})$ and ultralow power $(\leq 1 \mathrm{~mW})$ [2]. However, most energy harvesters are developed for ultra-low power and low power applications [6-10]. For example, Meehan et al. [6] tested the microbial fuel cell harvester integrated with power management circuit which is able to generate $1 \mathrm{~mW}$ for under water electronic devices. Kong et al. [7] tested the cantilever piezo harvester with Fly-back converter and MPPT circuitry to charge a super capacitor capable of delivering $8.4 \mathrm{~mW}$ at $47 \mathrm{~Hz}$ frequency. Yap et al. [8] tested the thermoelectric energy harvester (TEGl-4199-S.3) 
integrated with the DC-DC converter (LTC310S) for mobile charging using USB port. They tested their prototype using reusable heat pad and their harvester is capable of generating $150 \mathrm{mV}$ from $10{ }^{\circ} \mathrm{C}$ temperature difference but there is no discussion how long it can take to charge the mobile phone.

To increase power generation capacity, reliability and maintain the continuity of supply, energy harvesting has progressed from single energy source to hybrid energy harvesters. That is developed to harness energy from multiple sources for example combinations of solar, wind, vibration etc. and, often use multiple conversion techniques such as solar PV, thermoelectric, triboelectric, piezoelectric etc. [1-2], [5], [11-14]. For medium and high power applications, solar, wind or a hybrid solar-wind harvester are preferred [2], [4]. Other hybrid energy harvesters such as electromagnetic/piezo-electric are used in ultra-low and low power applications.

Various studies have investigated hybrid energy harvesters, including the combination of electromagnetic and piezoelectric energy harvesting mechanisms [5], [9-11], [15] and they demonstrated power delivery in range of $\mu \mathrm{W}$ to $\mathrm{mW}$. For example an energy harvester presented by Yang et al. [10] is capable of generating $176.19 \mu \mathrm{W}$ whilst Challa et al. [11] demonstrated a harvester that could generate $332 \mu \mathrm{W}$. Further an energy harvester presented by Xia et al. [10], [13] could generate up to $3.32 \mathrm{~mW}$ and, Kwon et al. [5] works demonstrated 5.76mW. Zhao et al. [14] introduced a hybrid energy harvester combing electromagnetic-piezoelectric principle capable of generating $16.55 \mathrm{~mW}$ for underwater applications. A hybrid energy harvester based on electromagnetic and solar energy harvesting was presented in J. Bito et al. [1] which can generate $15 \mu \mathrm{W}$ for a wireless sensor application. Sriramdas et al. [12] reported electrodynamic and piezoelectric hybrid harvester with a generating capacity of 1.7mW. Salauddin et al. [16] developed and fabricated a non-resonant hybrid energy generator combination of electromagnetic and tribo-electric nano-generator. Their fabricated prototype was capable of generating power from $0.74 \mathrm{~mW}$ to $2.9 \mathrm{~mW}$, from human motion, which could be exploited in wearable smart electronic applications. Habibzadeh et al. [2] presented a hybrid solar-wind harvester for high power application where power generated by the solar panel and the wind turbine are $24.2 \mathrm{~W}$ and $19.4 \mathrm{~W}$ respectively. Hassanalieragh et al. [17] also presented auto-wakeup solar energy harvester for medium and high power applications which was used to deliver $5 \mathrm{~W}, 10 \mathrm{~W}$ and $15 \mathrm{~W}$ power for embedded systems applications.

It is evident from this introduction and review, that numerous research investigations have been undertaken relating to low power hybrid energy harvesters [9], [11], [13] \& [15-16], however there has been less focus on medium power applications (1W-10W), such as in smart mobile phone charging applications. This paper presents our feasibility study of a medium power hybrid energy harvester based upon solar and thermoelectric harvesting targeting real-world applications, such as mobile phone charging. An individual energy harvester has been tested 
and analysed to evaluate performance and power delivering. The paper is organized as follows: Section 2 presents a background theory of Solar PV and Thermo-electric energy harvester. Section 3 discusses the tested prototype and presents the experimental results. Moreover the block diagram model of a solar PV has been built using Simulink to generate the I-V and P-V curves and the simulated results are compared with experimental values. Section 4 presents the measured efficiency and charging time for the Solar PV for powering smart mobile device. The Conclusion is presented in section 5, providing key achievements from this work and future areas of investigation.

\section{PV and Thermo-electric energy harvesters}

To undertake modeling and analysis it is necessary to create a mathematical model that accurately describe the non-linear I-V and P-V characteristics of solar PV module. Many models exhibit the characteristics of solar cells however in apply the commonly utilized models are the single diode equivalent circuit model (SDM), the double diode equivalent circuit model (DDM) and the triple diode equivalent circuit model. The SDM model is considered in this paper due to its simplicity and accuracy in defining the total $\mathrm{I}-\mathrm{V}$ and $\mathrm{P}-\mathrm{V}$ curve of a cell, module or cluster as a ceaseless perform for a given set of working conditions. Fig. 1 represents the simple single diode circuit configuration of a practical PV cell which comprises of a current source in parallel with a single diode and a shunt $\mathrm{R}_{\mathrm{SH}}$ and a series resistance $\mathrm{R}_{\mathrm{s}}$.

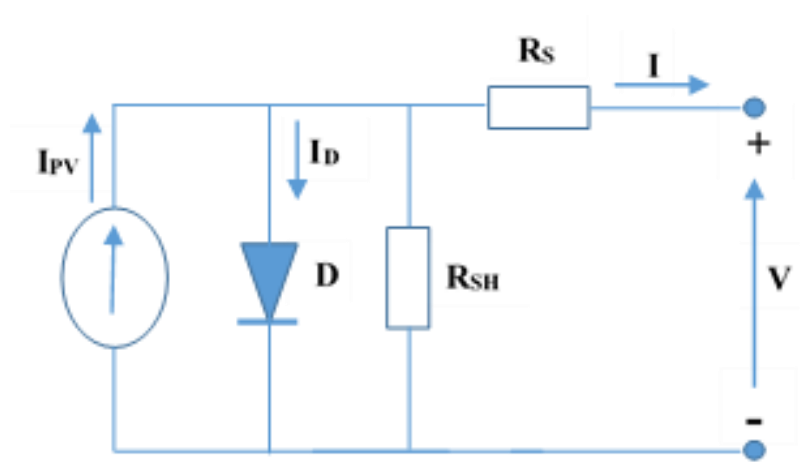

Fig. 1. Practical Single diode PV cell model

The expression of output current for the PV cell is given by [18];

$I=I_{P V}-I_{0}\left[\exp \left(\frac{q\left(V+R_{S} * I\right)}{n * K * T}\right)-1\right]-\frac{\left(V+R_{S} * I\right)}{R_{S H}}$

The SDM output current of the PV module can be defined by [19]; 
$I=I_{P V} * N_{P}-I_{0} * N_{P}\left[\exp \left(\frac{q\left(\frac{V}{N_{S}}+\frac{R_{S}}{N_{P}} * I\right)}{n * K * T}\right)-1\right]-\frac{\left(\frac{V * N_{P}}{N_{S}}+R_{S} * I\right)}{R_{S H}}$

Where the definitions of $q, n, k, I_{o}, I_{p v}, N_{p}, V, N_{s}$ and $I$ are described to appendix table.

The thermoelectric energy harvester is a solid-state device that converts temperature differences across dissimilar materials into electricity, based upon Seebeck effect. A typical thermoelectric power harvester as shown in Fig. 2 consists of two dissimilar metals, $\mathrm{p}$ and $\mathrm{n}$ type semiconductor materials, electrodes and a ceramic substrate which acts as the electrical insulator. The most common thermoelectric conductor materials are either based on bismuth telluride $\left(\mathrm{Bi}_{2} \mathrm{Te}_{3}\right)$ or lead telluride $(\mathrm{PbTe})$. As the heat flows from hot surface to cold surface, free electrons or holes are driven to the cold surface which develops an open circuit voltage across the terminal. The generated open circuit voltage can be defined by [20-21];

$V_{o c}=\alpha\left(T_{h}-T_{c}\right)$

Where the proportionality factor $(\alpha)$ called the Seebeck coefficient, and $T_{h}$ and $T_{C}$ are the hot and cool ends absolute kelvin temperatures.

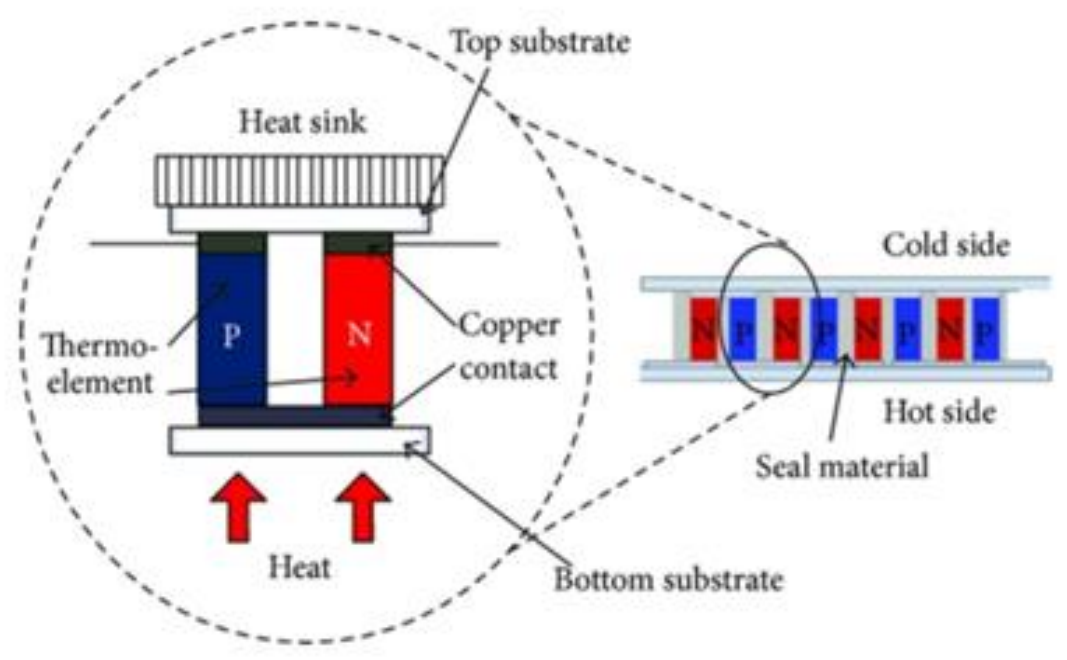

Fig. 2: Working principle of Thermoelectric Generator (Wang et al., 2013) [22].

A thermoelectric material's performance efficiency of converting heat to electricity is characterised by the dimensionless figure of merit, $Z T$ and it can be written by equation 4 [20-21];

$Z T=\frac{\alpha^{2} \sigma}{\lambda} T_{a v g}$

Where $\sigma$ is the electrical conductivity, $\lambda$ is the thermal conductivity and $T_{\text {avg }}$ is the absolute average 
temperature. There is no theoretical limit to $Z T$ and recent research suggests that ZT of new nanostructure thermoelectric materials could reach ZT values of between 2 to 3, which will open further applications for these materials. The relationship between ZT and the maximum efficiency for a thermoelectric element is expressed by $[20-21] ;$

$$
\eta_{\max }=\frac{T_{h}-T_{c}}{T_{h}} \frac{\sqrt{1+Z T_{a v g}}-1}{\sqrt{1+Z T_{a v g}}+\frac{T_{c}}{T_{h}}}
$$

\section{Experimental Set Up}

In this research we have demonstrated a hybrid energy harvester for charging a mobile phone. Fig. 3 shows the block diagram model of the hybrid energy harvester which consists of three types of energy harvesters including solar PV and thermoelectric, all including the power electronics circuitry. The following section discusses the characteristics and the performance of the solar and thermoelectric energy harvester.

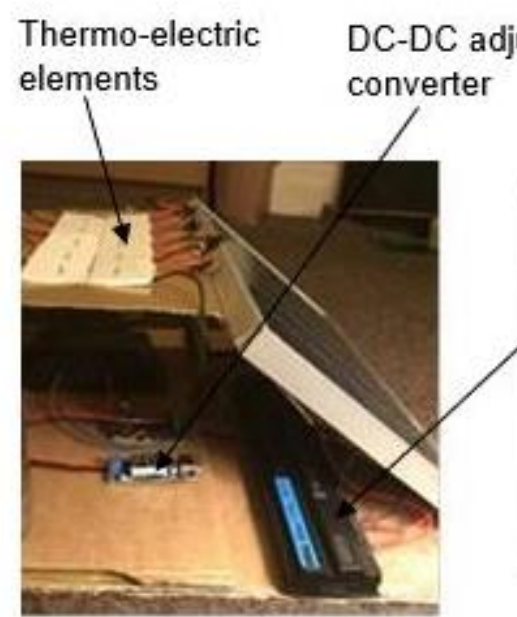

(a)

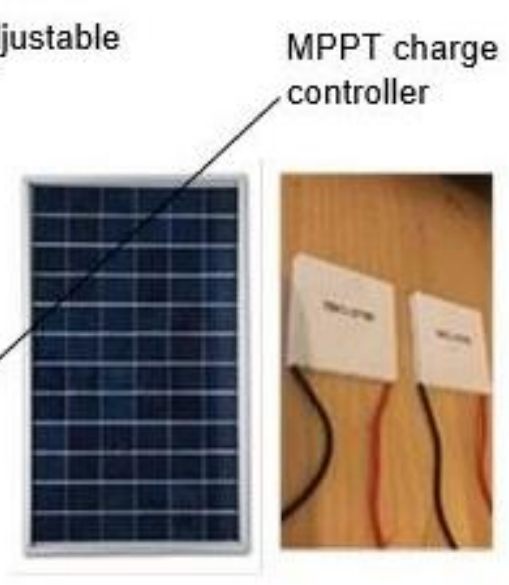

(b)

Fig. 3: (a) Tested hybrid energy harvester (b) Sources (Solar and Thermoelectric)

\subsection{Performance Analysis of the Solar PV Module}

With reference to the Eco-worthy P10X-CB-1 photovoltaic module as shown in Fig. 3, the module cell topology is 36 cells connected in series with an output voltage of 20.6 volts on open circuit under standard test conditions, (STC) [23] i.e. an irradiation level of $1000 \mathrm{Wm}^{-2}$, ambient air temperature $25^{\circ} \mathrm{C}$ and an air mass of 1.5. Data appertaining to other important PV module is shown at Table 1. 
The model of the PV module was built in MATLAB-Simulink and was based on equation (2) and other recent developments [18], the objective being to simulate I-V and P-V characteristics of this PV module under real test conditions (RTC).

Table 1: Tested PV module data sheet parameters

\begin{tabular}{ll}
\hline \hline \multicolumn{1}{c}{ Parameters } & Values \\
\hline Maximum power rating & $10.00 \mathrm{~W}$ \\
Maximum power point voltage & $17.30 \mathrm{~V}$ \\
Maximum power point current & $0.58 \mathrm{~A}$ \\
Rated voltage (open circuit) & $20.60 \mathrm{~V}$ \\
Rated Current (short circuit) & $0.68 \mathrm{~A}$ \\
Number of cells & 36.00 \\
Maximum Power Tolerance & $\pm 3.00 \%$ \\
Module size (L x W x H) & $337 \times 200 \times 18 \mathrm{~mm}$ \\
\hline \hline
\end{tabular}

Real test performance of the PV module was evaluated under a variety temperatures and irradiances in the range $300 \mathrm{Wm}^{-2}$ to $1000 \mathrm{Wm}^{-2}$. Data from a 72 hours period was used in order to compare with the data as generated by the simulation. A comparative analysis of real and simulation (voltage, current and power) is shown at Table 2 and at Fig. 4. Note: PV module performance at low irradiation levels is weak i.e. very low power is outputted. Also at Fig. 4 are the simulated graphs as obtained from other data relating to irradiance and temperatures obtained via real test conditions (RTC). The measurement has been carried out for fixed temperature with the variation of irradiation. Increase in temperature results in an increase in short circuit current and decrease the open circuit voltage, whilst an increase in irradiance increases both open circuit voltage and power output [18]. Though temperature has a significant influence on the power output of a photovoltaic module, solar irradiation has a high influence on the resultant power output of a PV module, because irradiation is proportional to current. The detailed discussion of how Irradiation and temperature affect the PV parameters can be found in the author's paper [18] on this subject. 
Table 2: Comparative analysis between measured outdoor and the model

\begin{tabular}{|c|c|c|c|}
\hline Parameters & "Model results & "Experimental results & Error $(\%)$ \\
\hline \multicolumn{4}{|l|}{ (1) For $\mathrm{G}=1000 \mathrm{~W} / \mathrm{m}^{2}, \mathrm{~T}=298 \mathrm{~K}$} \\
\hline Maximum power $(\mathrm{W})$ & 10.12 & 9.15 & 9.50 \\
\hline Maximum power point voltage $(\mathrm{V})$ & 17.05 & 17.60 & 3.00 \\
\hline Maximum power point current (A) & 0.57 & 0.50 & 0.00 \\
\hline Voltage at open circuit $(\mathrm{V})$ & 20.50 & 21.20 & 3.30 \\
\hline Current at short circuit (A) & 0.65 & 0.62 & 4.00 \\
\hline \multicolumn{4}{|l|}{ (2) For $\mathrm{G}=500 \mathrm{~W} / \mathrm{m}^{2}, T=298 \mathrm{~K}$} \\
\hline Maximum power $(\mathrm{W})$ & 4.61 & 3.86 & 16.00 \\
\hline Maximum power point voltage (V) & 16.27 & 16.10 & 1.00 \\
\hline Maximum power point current (A) & 0.29 & 0.26 & 10.00 \\
\hline Voltage at open circuit $(\mathrm{V})$ & 19.57 & 20.80 & 6.00 \\
\hline Current at short circuit (A) & 0.30 & 0.27 & 10.00 \\
\hline \multicolumn{4}{|l|}{ (3) For $\mathrm{G}=300 \mathrm{~W} / \mathrm{m}^{2}, \mathrm{~T}=298 \mathrm{~K}$} \\
\hline Maximum power $(\mathrm{W})$ & 2.70 & 2.30 & 14.00 \\
\hline Maximum power point voltage $(\mathrm{V})$ & 16.09 & 15.30 & 5.00 \\
\hline Maximum power point current (A) & 0.17 & 0.15 & 11.00 \\
\hline Voltage at open circuit $(\mathrm{V})$ & 18.86 & 19.50 & 3.40 \\
\hline Current at short circuit (A) & 0.19 & 0.16 & 15.00 \\
\hline
\end{tabular}




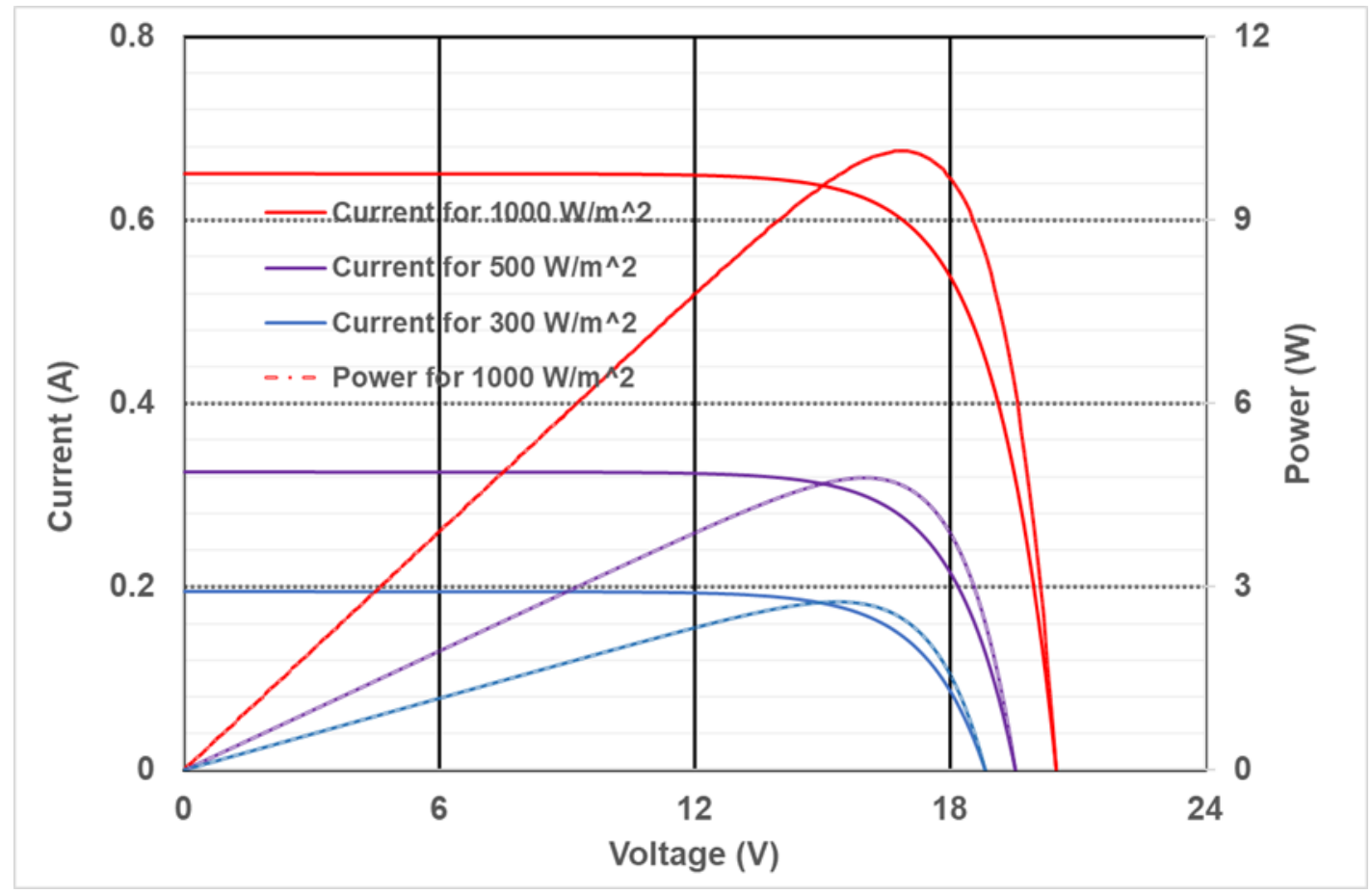

Fig. 4. Simulated I-V and P-V characteristics with the variation of irradiation

\subsection{Module Performance Evaluation of the Thermoelectric Module}

Eight thermoelectric elements TEC1-12706 are connected in series with a variable resistor bank. It can be seen from Fig. 5 that the hot surface of the thermoelectric element is attached with the aluminium foil tray and the cold surface is attached with the copper sheet. Hot water has been poured to the tray as a heat source. The output voltages and the temperature for the hot and cold surfaces have been measured with the variation of the load resistances to understand the variation of load voltage and power. The measured load voltage and load power for different temperature gradient have been plotted in Fig. 6 with the variation of load resistance. It can be seen from the Fig. 6 that the harvester is capable to deliver $5.3 \mathrm{~mW}, 2.048 \mathrm{~mW}$ and $0.84 \mathrm{~mW}$ maximum load power from $50^{\circ} \mathrm{C}, 40^{\circ} \mathrm{C}$ and $30^{\circ} \mathrm{C}$ temperature gradient respectively however the optimum load for maximum power is around $200 \Omega$ for all three cases.

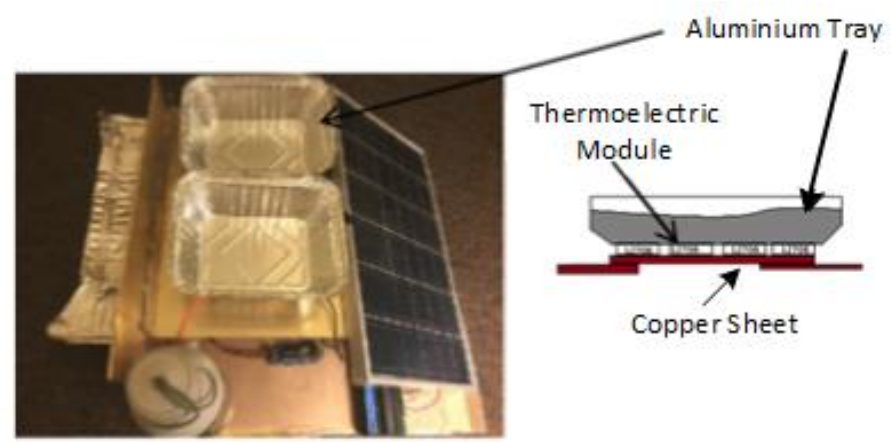

Fig. 5: Experimental setup for thermoelectric energy harvester 


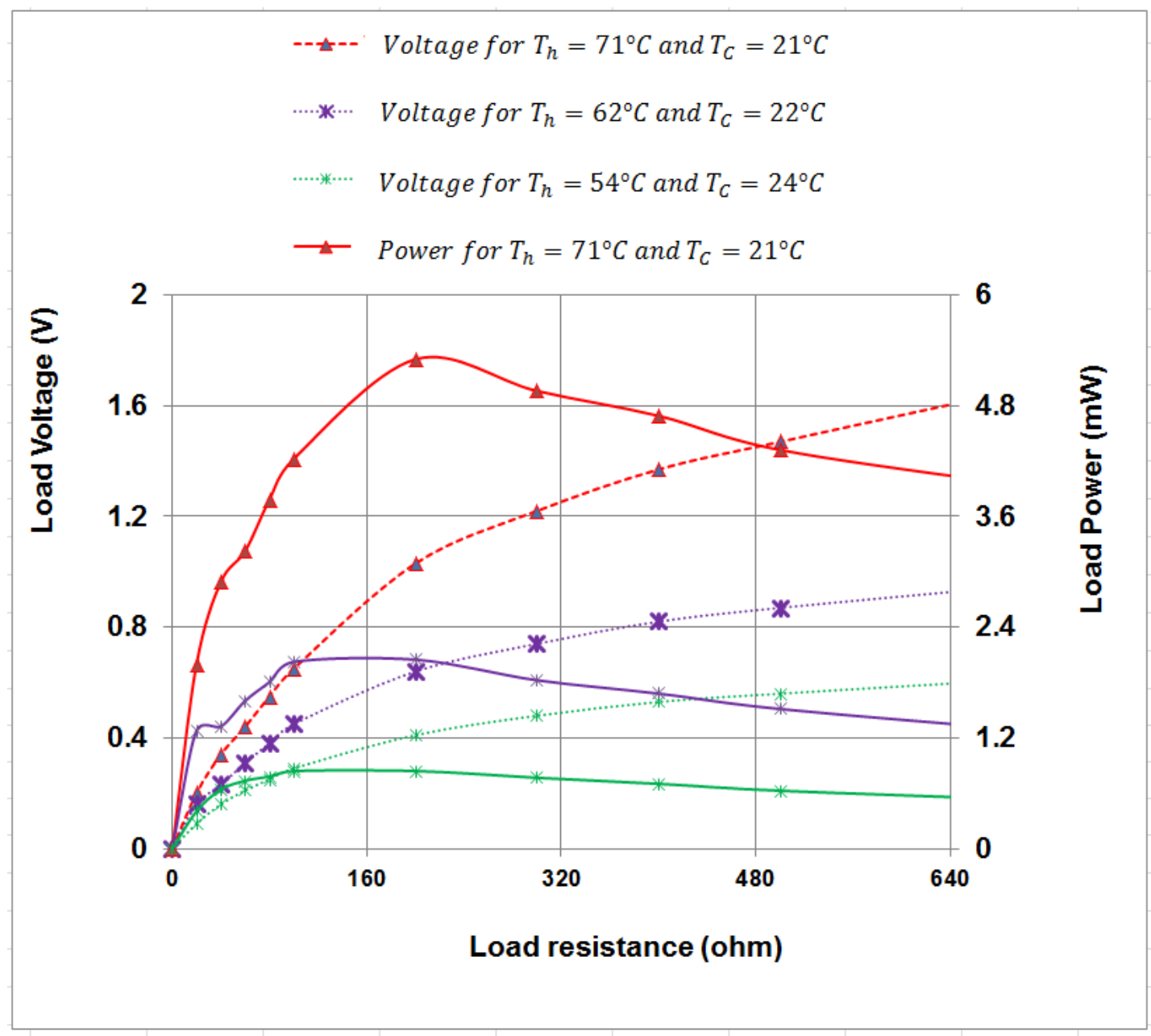

Fig. 6. Measured output voltage and power with variation of load resistance for thermo electric harvester

\section{Application Overview}

The complete experimental setup to charge the smart phone is shown in the Fig. 7. It can be seen from the figure that a portable solar module is integrated with DC/DC adjustable converter and CMTP02 3A solar charge controller. The output of the charge controller is connected with the USB buck controller which charges the smart phone Xiaomi Redmi Note 2 . The PV output current $\left(I_{1}\right)$ and voltage $\left(V_{1}\right)$ and, the charge controller output current $\left(I_{2}\right)$ and voltage $\left(V_{2}\right)$ have been measured as shown in Fig. 8 for 50 minutes while the Wi-Fi was on to investigate the efficiency and charging capacity of the solar harvester. This provides the estimate of total required time to fully charge the mobile phone battery.

The outdoor measurements have been carried out in a sunny day at outside of ECB building, Coventry University. The measured temperature was $22^{\circ} \mathrm{C}$ and the measured irradiation level varied between $850 \mathrm{Wm}^{-2}$ and $980 \mathrm{Wm}^{-2}$. The measured results indicate that the PV panel is capable of charging the battery to $16 \%$ of full 
charge in 50mins. The measured output power of the solar panel and the output power of the MPPT charge controllers are $4.39 \mathrm{~W}$ and $3.32 \mathrm{~W}$ respectively. The calculated stored energy of the smart phone battery is $7 \mathrm{~kJ}$ and charging efficiency is $53 \%$.

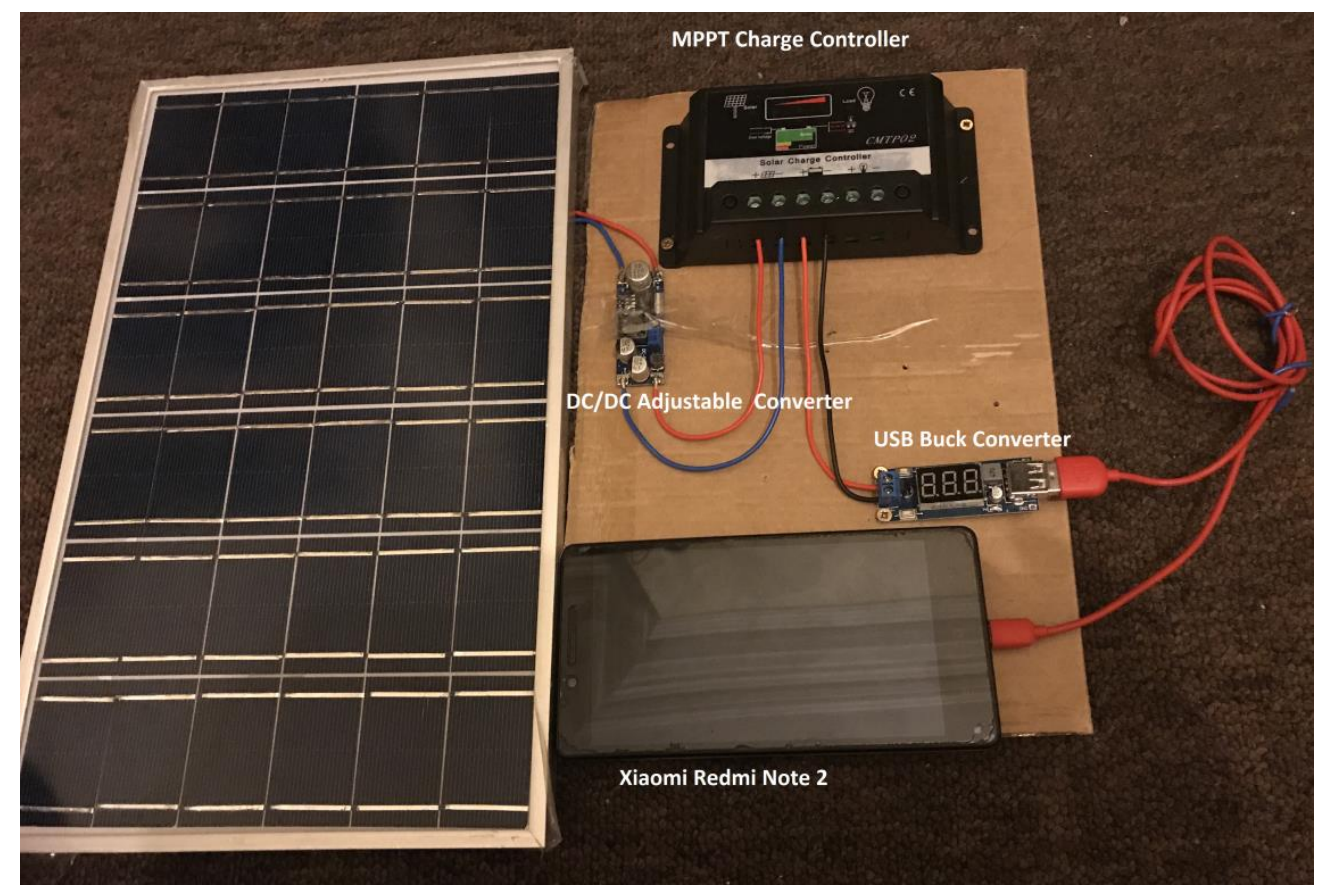

Fig. 7. Solar energy harvester integrated with charge controller and USB converter for mobile charging

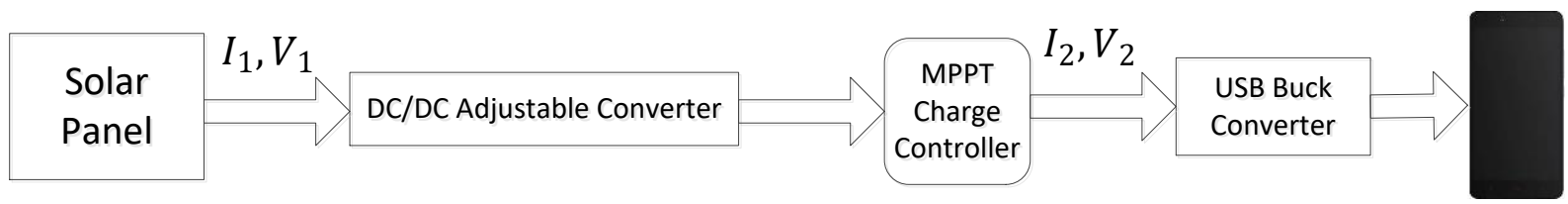

Fig. 8.Charging and Efficiency Measurement

\section{Conclusions}

This paper presented two energy harvesters namely thermoelectric and solar PV and, analysed their performances for charging applications. There is no minimum amount of current requirement to charge a battery, mobile phone or tablet but the voltage should be nearly $4.5 \mathrm{~V}$ to $5 \mathrm{~V}$. However, the speed of charging will depend on the current level and it will take longer period to charge it fully if the current level is very low. Charging mobile phone from laptop/computer through the USB2.0 port takes around double time compare to the adapter since the adapter provides $1 \mathrm{~A}$ current whereas laptop port provides only $0.5 \mathrm{~A}$ current. The measured results show that 
thermoelectric module can generate maximum $5.2 \mathrm{~mW}$ power when the temperature difference is $50^{\circ}$ Celsius. Thus, it can be concluded that the thermoelectric module of practical size is not capable of generating sufficient power to charge power to smart mobile phone which requires about 5-10W power. So, thermoelectric module is not a feasible option for these applications. Further research is required on power management circuitry for thermoelectric energy harvester to extract maximum power. Tuning the parameters and impedance matching of an energy harvester both are the difficult design challenge. On the other hand, solar PV modules generated about $10 \mathrm{~W}(9.65 \mathrm{~W}$ in simulation and $8.80 \mathrm{~W}$ in experimentation) at MPP (maximum power point) when the irradiance was $1000 \mathrm{~W} / \mathrm{m}^{2}$.Thus, only solar PV can generate sufficient power from the environment for these applications.

\section{Appendix A}

PV module photo current, $\mathrm{I}_{\mathrm{pv}}(\mathrm{A})$

Diode reverse saturation current, $\mathrm{I}_{\mathrm{o}}(\mathrm{A})$

Module operating temperature, $\mathrm{T}\left({ }^{\mathrm{o}} \mathrm{K}\right)$.

Electron charge, $\mathrm{q}\left(1.6 \times 10^{-19} \mathrm{C}\right)$.

Boltzman constant, $\mathrm{K}\left(1.3805 \times 10^{-23} \mathrm{~J} / \mathrm{K}\right)$.

PV module output voltage, V (Volts).

PV module series resistance, $R_{s}(\Omega)$.

Number of cells connected in series, $\mathrm{N}_{\mathrm{s}}$

Number of cells connected in parallel, $\mathrm{N}_{\mathrm{p}}$

\section{Acknowledgements}

There was no funding of this work.

\section{References}

[1] Bito, J.; Bahr, R.; Hester, J. G.; Nauroze, S. A.; Georgiadis, A.; Tentzeris, M. M. A Novel Solar and Electromagnetic Energy Harvesting System With a 3-D Printed Package for Energy Efficient Internet-ofThings Wireless Sensors. IEEE Trans. Microw. Theory Tech. 2017, 65, 1831-1842, doi:10.1109/TMTT.2017.2660487.

[2] Habibzadeh, M.; Hassanalieragh, M.; Ishikawa, A.; Soyata, T.; Sharma, G. Hybrid Solar-Wind Energy Harvesting for Embedded Applications: Supercapacitor-Based System Architectures and Design Tradeoffs. IEEE Circuits Syst. Mag. 2017, 17, 29-63.

[3] Dyo, V.; Ellwood, S. A.; Macdonald, D. W.; Markham, A.; Trigoni, N.; Wohlers, R.; Mascolo, C.; Pásztor, B.; Scellato, S.; Yousef, K. WILDSENSING: Design and deployment of a sustainable sensor network for wildlife monitoring. ACM Trans. Sens. Netw. TOSN 2012, 8, 29.

[4] Habibzadeh, H.; Qin, Z.; Soyata, T.; Kantarci, B. Large-Scale Distributed Dedicated-and Non-Dedicated Smart City Sensing Systems. IEEE Sens. J. 2017, 17, 7649-7658. 
[5] Kwon, D. S.; Ko, H. J.; Kim, J. Piezoelectric and electromagnetic hybrid energy harvester using two cantilevers for frequency up-conversion. In 2017 IEEE 30th International Conference on Micro Electro Mechanical Systems (MEMS); 2017; pp. 49-52.

[6] Meehan, A.; Gao, H.; Lewandowski, Z. Energy Harvesting With Microbial Fuel Cell and Power Management. IEEE Transactions on Power Electronics. 2016, 26(1).

[7] Kong, N., Ha, D.S., 2012. Low-power design of a self-powered piezoelectric energy harvesting system with maximum power point tracking. IEEE Trans. Power Electron. 27, 2298-2308.

[8] Yap, Y.Z., Naayagi, R.T., Woo, W.L., 2016. Thermoelectric energy harvesting for mobile phone charging application, in: 2016 IEEE Region 10 Conference (TENCON). IEEE, pp. 3241-3245.

[9] Yang, B.; Lee, C.; Kee, W. L.; Lim, S.-P. Hybrid energy harvester based on piezoelectric and electromagnetic mechanisms. J. MicroNanolithography MEMS MOEMS 2010, 9, 023002.

[10] Xia, H.; Chen, R.; Ren, L. Parameter tuning of piezoelectric-electromagnetic hybrid vibration energy harvester by magnetic force: Modeling and experiment. Sens. Actuators Phys. 2017, 257, 73-83, doi:10.1016/j.sna.2017.01.026.

[11] Challa, V. R.; Prasad, M. G.; Fisher, F. T. A coupled piezoelectric-electromagnetic energy harvesting technique for achieving increased power output through damping matching. Smart Mater. Struct. 2009, 18, 095029.

[12] Sriramdas, R.; Pratap, R. An Experimentally Validated Lumped Circuit Model for Piezoelectric and Electrodynamic Hybrid Harvesters. IEEE Sens. J. 2017, PP, 1-1, doi:10.1109/JSEN.2017.2776242.

[13] Xia, H.; Chen, R.; Ren, L. Analysis of piezoelectric-electromagnetic hybrid vibration energy harvester under different electrical boundary conditions. Sens. Actuators Phys. 2015, 234, 87-98, doi:10.1016/j.sna.2015.08.014.

[14] Zhao, J.; Zhang, H.; Su, F.; Yin, Z. A novel model of piezoelectric- electromagnetic hybrid energy harvester based on vortex-induced vibration. In 2017 International Conference on Green Energy and Applications (ICGEA); 2017; pp. 105-108.

[15] Hamid, R.; Yuce, M. R. A wearable energy harvester unit using piezoelectric-electromagnetic hybrid technique. Sens. Actuators Phys. 2017, 257, 198-207, doi:10.1016/j.sna.2017.02.026.

[16] Salauddin, M.; Toyabur, R. M.; Maharjan, P.; Rasel, M. S.; Kim, J. W.; Cho, H.; Park, J. Y. Miniaturized Springless Hybrid Nanogenerator for Powering Portable and Wearable Electronic Devices from HumanBody-Induced Vibration. Nano Energy 2018.

[17] Hassanalieragh, M.; Soyata, T.; Nadeau, A.; Sharma, G. UR-SolarCap: An open source intelligent autowakeup solar energy harvesting system for supercapacitor-based energy buffering. IEEE Access 2016, 4, 542-557.

[18] Abdullahi, N.; Saha, C.; Jinks, R. Modelling and performance analysis of a silicon PV module. J. Renew. Sustain. Energy 2017, 9, 033501.

[19] Yuan, X.; He, Y.; Liu, L. Parameter extraction of solar cell models using chaotic asexual reproduction optimization. Neural Comput. Appl. 2015, 26, 1227-1239.

[20] Musiall, M.; Borcuch, M.; Wojciechowski, K. Performance calculations of thermoelectric module p-type leg composed of (Bi2Te3) x (Sb2Te3) 1-x. In E3S Web of Conferences; EDP Sciences, 2016; Vol. 10, p. 00062.

[21] Kim, H. S.; Liu, W.; Ren, Z. Efficiency and output power of thermoelectric module by taking into account corrected Joule and Thomson heat. J. Appl. Phys. 2015, 118, 115103.

[22] Wang, W., Cionca, V., Wang, N., Hayes, M., O’Flynn, B., O’Mathuna, C., 2013. Thermoelectric energy harvesting for building energy management wireless sensor networks. Int. J. Distrib. Sens. Netw. 9, 232438.

[23] Energetica What does Standard Test Conditions (STC) mean? Available online: http://www.energeticapv.com/index.php?id=447 (accessed on Jun 26, 2018). 